\title{
An Innovative Beneficial Reclamation of Flue Gas Desulfurization Brine Using Bipolar Membrane Electrodialysis Technique
}

\author{
Min Xia, Chunsong Ye ${ }^{*}$ Rong Cao, Haoyu Huang, Jianwei Huang \\ School of Power and Mechanical Engineering, Wuhan University, Wuhan 430072, Hubei, China \\ *E-mail: chunsongye@126.com
}

doi: $10.20964 / 2018.06 .04$

Received: 9 August 2017 / Accepted: 21 March 2018 / Published: 10 May 2018

Flue gas desulfurization (FGD) brine containing high salinity poses a significant challenge to the implementation of environmental policy in china. In this work, an innovative alternative approach of bipolar membrane electrodialysis (BMED) technique has been proposed to effectively reuse this brine by the acid and base production on the premise of zero emission requirements. The experimental results demonstrate that the high acid and base concentrations in excess of $1.0 \mathrm{~mol} / \mathrm{L}$ can be obtained with the satisfactory desalination. Higher initial salt concentration shows nearly no significant change on current efficiency, acid/base concentration and acid volume. Nevertheless, appropriate concentration for $\times 2$ of FGD brine is necessary and beneficial for acid/base production by the decrease of energy consumption from 2.34 to $2.14 \mathrm{Kwh} / \mathrm{kgNaOH}$. Additionally, the ions migration between $\mathrm{Cl}^{-}$ and $\mathrm{SO}_{4}{ }^{2-}$ indicates high purity $\mathrm{HCl}$ with little $\mathrm{H}_{2} \mathrm{SO}_{4}$ contamination can be obtained if the initial salt concentration of FGD brine is improved in the earlier acid production. In conclusion, BMED presents a high potential for FGD brine treatment in view of environmentally friendly as well as attractive economic benefit.

Keywords: flue gas desulfurization brine; bipolar membrane electrodialysis; acid/base production; desalination

\section{$\underline{\text { FULL TEXT }}$}

(C) 2018 The Authors. Published by ESG (www.electrochemsci.org). This article is an open access article distributed under the terms and conditions of the Creative Commons Attribution license (http://creativecommons.org/licenses/by/4.0/). 